\title{
ANTIOXIDANT ACTIVITIES OF PROTEIN HYDROLYSATES OBTAINED FROM THE HOUSEFLY LARVAE
}

\author{
Huan Zhang, Pan Wang, Ai-Jun Zhang, Xuan Li, Ji-Hong Zhang, \\ QI-LIAN QIN* and Yi-JUN WU* \\ State Key Laboratory of Integrated Management of Pest Insects \& Rodents, Institute of Zoology, \\ Chinese Academy of Sciences, Beijing 100101, China
}

(Received: January 8, 2016; accepted: March 18, 2016)

The housefly is an important resource insect and the housefly larvae are ideal source of food additives.
The housefly larvae protein hydrolysates were obtained by enzymatic hydrolysis by alcalase and neutral
proteinase. Their antioxidant activities were investigated, including the superoxide and hydroxyl radical-
scavenging activity, 1,1-diphenyl-2-picrylhydrazyl (DPPH) scavenging activity, reducing power and
metal chelating activity. The antioxidant activities of both hydrolysates increased with their increasing
concentrations. The alcalase hydrolysate (AH) showed higher scavenging activities against hydroxyl
radical and superoxide anion radical at low concentrations and higher metal-chelating activity than the
neutral proteinase hydrolysate (NPH). The NPH exhibited higher scavenging activity against DPPH free
radical and higher reducing power than the AH. Both hydrolysates showed more than $50 \%$ superoxide
anion radical-scavenging activity at $10 \mu \mathrm{g} / \mathrm{mL}$. These results indicate that both housefly larvae protein
hydrolysates display high antioxidant activities and they could serve as potential natural antioxidant food
additives.

Keywords: Housefly - protein hydrolysates - food additive - free radical scavenging activity

\section{INTRODUCTION}

Free radicals are known to be harmful to human and animal health. They are unstable and react readily with other groups or substances in the body, resulting in cell damage or tissue injury and hence diseases [1,2]. Antioxidants are often used in food to eliminate the effects of free radicals and to inhibit lipid oxidation, which could result in decreased quality of food and even produce potentially toxic products [3, 4]. However, synthetic antioxidants have caused humerous negative consumer perception because of long-term safety issues [5]. Therefore, it is important to find potential natural antioxidants, especially food-derived natural antioxidants $[5,6]$. Various antioxidant activities of protein hydrolysates from different resources, have been reported mainly including aquatic products such as jellyfish, skin of sole and squid, and yellow stripe trevally [7-12]. The antioxidant activities measured included the superoxide anion radical-scavenging activity, hydroxyl radical-scavenging activity, 1,1-diphenyl-

\footnotetext{
*Corresponding authors; e-mail addresses: wuyj@ioz.ac.cn; qinql@ioz.ac.cn
} 
2-picrylhydrazyl (DPPH) free radical-scavenging activity, reducing power and metal chelating activity.

The housefly, Musca domestica (Diptera Muscidae), is one of the best known resource insects. Due to its short life cycle, high fecundity and high activity to convert organic waste into useful materials, it has been exploited to obtain high-quality protein, chitin and chitosan $[13,14]$. A number of laboratory work has mainly focused on the extraction and determination of the bioactivities of protein, chitosan, and antipeptides from the housefly $[15,16]$. However, little information is available about the antioxidant activities of the housefly larvae protein hydrolysates.

Therefore, the objective of this study was to evaluate the antioxidant and free radical-scavenging activities of the housefly protein hydrolysates prepared with alcalase and neutral proteinase. Different measurements, including the scavenging effect on free radicals, reducing power, and ferrous ion-chelating activity were used to evaluate their antioxidant activities.

\section{MATERIALS AND METHODS}

\section{Chemicals and enzymes}

Potassium ferricyanide, ferrous chloride, 2-thiobarbituric acid (TBA) $\beta$-nicotinamide adenine dinucleotide (NADH) and hydrogen peroxide $\left(\mathrm{H}_{2} \mathrm{O}_{2}\right)$ were purchased from Sinopharm Chemical Reagent Co., Ltd (Shanghai, China). Deoxyribose, phenazine methosulfate (PMS), 2,2-dipheny-1-picryhydrazyl (DPPH), Nitro blue tetrazolium (NBT) and 3-(2-pyridyl)-5, 6-bis (4-pheny-sulfonic acid)-1,2,4-triazine (ferrozine) were purchased from Sigma Chemical Co. (St. Louis, MO, USA). The alcalase and neutral proteinase were purchased from Beijing Aoboxing Biotech Co., Ltd (Beijing, China). Polypeptide SDS-PAGE molecular weight standards were purchased from Bio-Rad Laboratories, Inc. (Hercules, CA, USA). All other chemicals and reagents used were of analytical grade.

\section{Preparation of the housefly larvae protein hydrolysates}

Four-day housefly larvae were isolated from waste feedstuff, rinsed and boiled for 10-15 min. Then the insects were smashed with a home juicer and freeze-dried. Lipid in the dry larvae powder was removed using 2055 Soxtec Avanti manual system (FOSS, Denmark). The defatted powder was dispersed in distilled water (1:20, w/v) by stirring, and then the $\mathrm{pH}$ was adjusted to the respective optimal value for the enzymatic hydrolysis. The mixture was heated to $100^{\circ} \mathrm{C}$ for $30 \mathrm{~min}$ before enzymatic digestion. Hydrolysis was carried out by using the proteinases with an enzyme-substrate ratio of $0.5 \mathrm{AU} / \mathrm{g}$ at $40{ }^{\circ} \mathrm{C}$. The hydrolysis reaction was stopped after $6 \mathrm{~h}$ by heating to $90{ }^{\circ} \mathrm{C}$ for $30 \mathrm{~min}$. The mixture was then cooled down to room temperature 
and adjusted to $\mathrm{pH}$ 7.0. The soluble fraction was filtered, freeze-dried and stored at $-20{ }^{\circ} \mathrm{C}$ before further analysis.

\section{Tricine-SDS-PAGE of the hydrolysates}

The housefly larvae protein hydrolysates were analyzed by Tricine-SDS-PAGE according to Schägger [17], using a 4\% stacking gel, a 10\% separating gel and a $16.5 \%$ separating gel. The gels were stained with Coomassie brilliant blue G250 for $1 \mathrm{~h}$. Then the gel was destained twice in $10 \%$ acetic acid with each incubation time of $45 \mathrm{~min}$.

\section{Amino acids analysis}

The hydrolysates samples were subjected to acid hydrolysis with $5 \mathrm{~mL}$ of $6 \mathrm{M} \mathrm{HCl}$ under nitrogen atmosphere for $24 \mathrm{~h}$ at $110{ }^{\circ} \mathrm{C}$ to measure the amino acids except tryptophan (Tyr) and cysteine (Cys). Cysteine was determined separately by acid analysis of the oxidation product of cysteine, cysteic acid, obtained by using the performic acid method by Moore [18]. For tryptophan, the samples were hydrolyzed by $4.2 \mathrm{M} \mathrm{NaOH}$ for $24 \mathrm{~h}$ at $110{ }^{\circ} \mathrm{C}$ and then both products were used to measure the tryptophan separately. All amino acids were determined with 8900 amino acid Analyzer (Hitachi, Japan) and the amino acid composition was indicated as g (amino acid)/100 g (hydrolysate).

\section{Determination of scavenging activity against hydroxyl radical}

The hydroxyl radical-scavenging activity was assessed using the method of Halliwell et al. [19]. The hydroxyl radical-scavenging activity was calculated as follows:

$$
\text { Scavering activity }(\%)=\frac{A_{0}-\left(A_{1}-A_{2}\right)}{A_{0}} \times 100 \%
$$

where $A_{0}$ indicates the absorbance of the blank (distilled water instead of samples), $A_{1}$ is the absorbance of the mixture containing samples, and $A_{2}$ is the absorbance of the mixture without deoxyribose.

\section{Determination of scavenging activity against superoxide anion radical}

The superoxide anion radical-scavenging activity of samples was measured according to Yu et al. [11]. The scavenging activity of samples against superoxide anion radical was calculated by the following equation: 


$$
\text { Scavering activity }(\%)=\frac{A_{0}-A_{1}}{A_{0}} \times 100 \%
$$

where $A_{0}$ indicates the absorbance of the control (without samples), $A_{1}$ is the absorbance of the mixture containing samples.

\section{Determination of scavenging activity against DPPH free radical}

The DPPH radical-scavenging activity was assayed employing the reported method [18]. The scavenging activity was calculated with the following formula:

$$
\text { Scavering activity }(\%)=\frac{A_{0}-\left(A_{1}-A_{2}\right)}{A_{0}} \times 100 \%
$$

where $A_{0}$ indicates the absorbance of the blank (distilled water instead of samples), $A_{1}$ is the absorbance of the mixture containing samples, and $A_{2}$ is the absorbance of the mixture without DPPH.

\section{Determination of reducing power}

The reducing power of samples was determined with the method of Oyaizu [20]. Increased absorbance of the reaction mixture indicated increased reducing power.

\section{Assay of metal-chelating activity}

The chelating of ferrous ions by the samples was estimated by the method of Decker and Welsh [21]. Chelating activity (\%) was calculated as follows:

$$
\text { Scavering activity }(\%)=\frac{A_{0}-\left(A_{1}-A_{2}\right)}{A_{0}} \times 100 \%
$$

where $A_{0}$ is the absorbance of the control and $A_{1}$ was the absorbance in the presence of samples.

\section{Statistical analysis}

One-way analysis of variance was carried out by using the SPSS computer program (SPSS Statistical Software, Inc., Chicago, IL, USA). 


\section{RESULTS AND DISCUSSION}

\section{Characteristics of the housefly larvae protein hydrolysates}

Using Tricine SDS-PAGE, we analyzed the molecular weight of the housefly larvae protein hydrolysates produced by alcalase and neutral proteinase (Fig. 1). Both alcalase hydrolysate $(\mathrm{AH})$ and neutral proteinase hydrolysate $(\mathrm{NPH})$ contained polypeptide bands below $6.5 \mathrm{kDa}$. However, NPH (Fig. 1c) bands were less intense than that of $\mathrm{AH}$ (Fig. 1b), probably due to the reason that smaller peptides passed through the electrophoresis gel.

In Table 1 the amino acid composition of the AH and NPH is presented, which were similar in general. The total amount of amino acid was 56.1, $64.4 \mathrm{~g}$ per $100 \mathrm{~g}$ of sample for the AH and NPH, respectively. The differences of the amino acid composition and total amino acid content between the two hydrolysates may partly be caused by the neutralization process, in which some polypeptides were precipitated and filtered out. The peptides with the amino acids of His, Met, Cys, Pro, Ala or Gly are believed to have the radical-scavenging activities [22-24] and free radical quenching has been reported to be the main antioxidant mechanism. Thus the antioxidant activities of the housefly larvae hydrolysates were investigated accordingly.

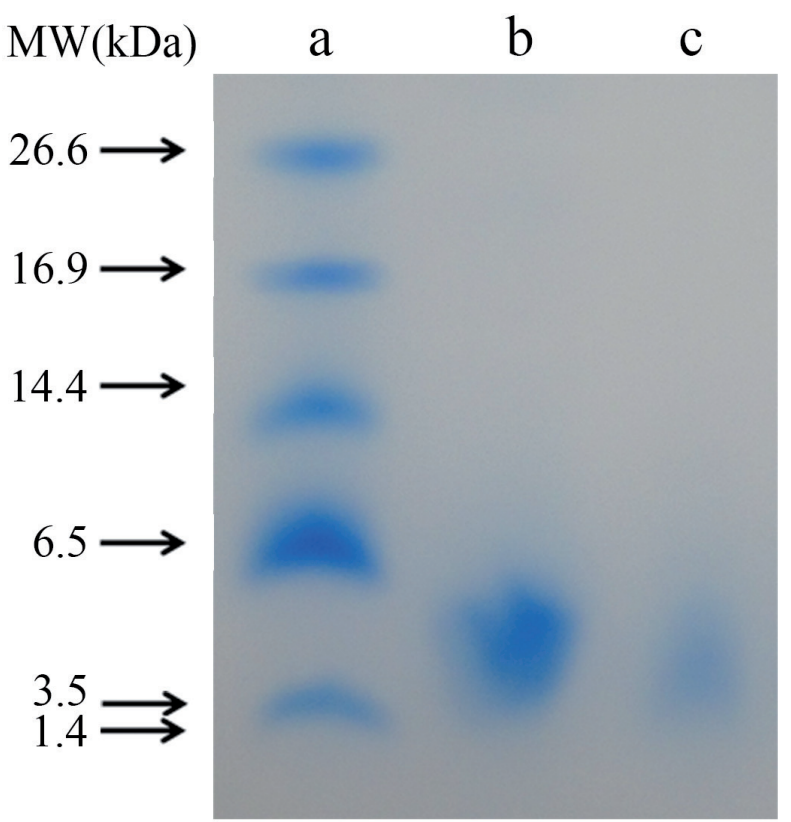

Fig. 1. Electrophoretic analysis of housefly larvae protein hydrolysates (Tricine-SDS-PAGE). (a) molecular weight marker; (b) alcalase hydrolysate; (c) neutral proteinase hydrolysate 
Table 1

Amino acid composition of the housefly larvae protein hydrolysates (g/100 g hydrolysated sample)

\begin{tabular}{|c|c|c|}
\hline Amino acids & Alcalase hydrolysate & $\begin{array}{c}\text { Neutral proteinase } \\
\text { hydrolysate }\end{array}$ \\
\hline Asp & 6.0 & 6.9 \\
\hline Thr & 2.7 & 2.8 \\
\hline Ser & 2.5 & 2.5 \\
\hline Glu & 8.8 & 10.0 \\
\hline Gly & 2.9 & 3.2 \\
\hline Ala & 3.5 & 3.7 \\
\hline Val & 3.1 & 3.5 \\
\hline Met & 1.0 & 1.9 \\
\hline Ile & 2.0 & 2.3 \\
\hline Leu & 4.3 & 4.7 \\
\hline Tyr & 3.5 & 4.5 \\
\hline Phe & 3.4 & 4.1 \\
\hline Lys & 5.2 & 6.0 \\
\hline His & 1.7 & 1.9 \\
\hline Arg & 2.7 & 3.7 \\
\hline Pro & 2.2 & 2.2 \\
\hline Trp & 0.3 & 0.1 \\
\hline Cys & 0.3 & 0.4 \\
\hline Total & 56.1 & 64.4 \\
\hline & & \\
\hline
\end{tabular}

\section{Hydroxyl radical scavenging activity of the protein hydrolysates}

Hydroxyl radical causes severe damage to the biomacromolecules and consequently aging and diseases [25]. As shown in Figure 2A, the AH showed slightly higher hydroxyl radical-scavenging activity than the NPH at the concentration of $0.2-0.6 \mathrm{mg} /$ $\mathrm{mL}$. At the final concentration of $1.0 \mathrm{mg} / \mathrm{mL}$, the $\mathrm{AH}$ and $\mathrm{NPH}$ exhibited $59.5 \%$ and $60.7 \%$ scavenging activity on hydroxyl radical, respectively. The high hydroxyl radical-scavenging activities of both housefly larvae protein hydrolysates suggested that they may serve as good hydroxyl radical scavenger.

\section{Superoxide anion radical scavenging activity of the hydrolysates}

Superoxide anion radical is the source of free radicals formed in vivo in cellular oxidation reactions that produce hydrogen peroxide and hydroxyl radical through dismutation and other types of reaction [26]. 

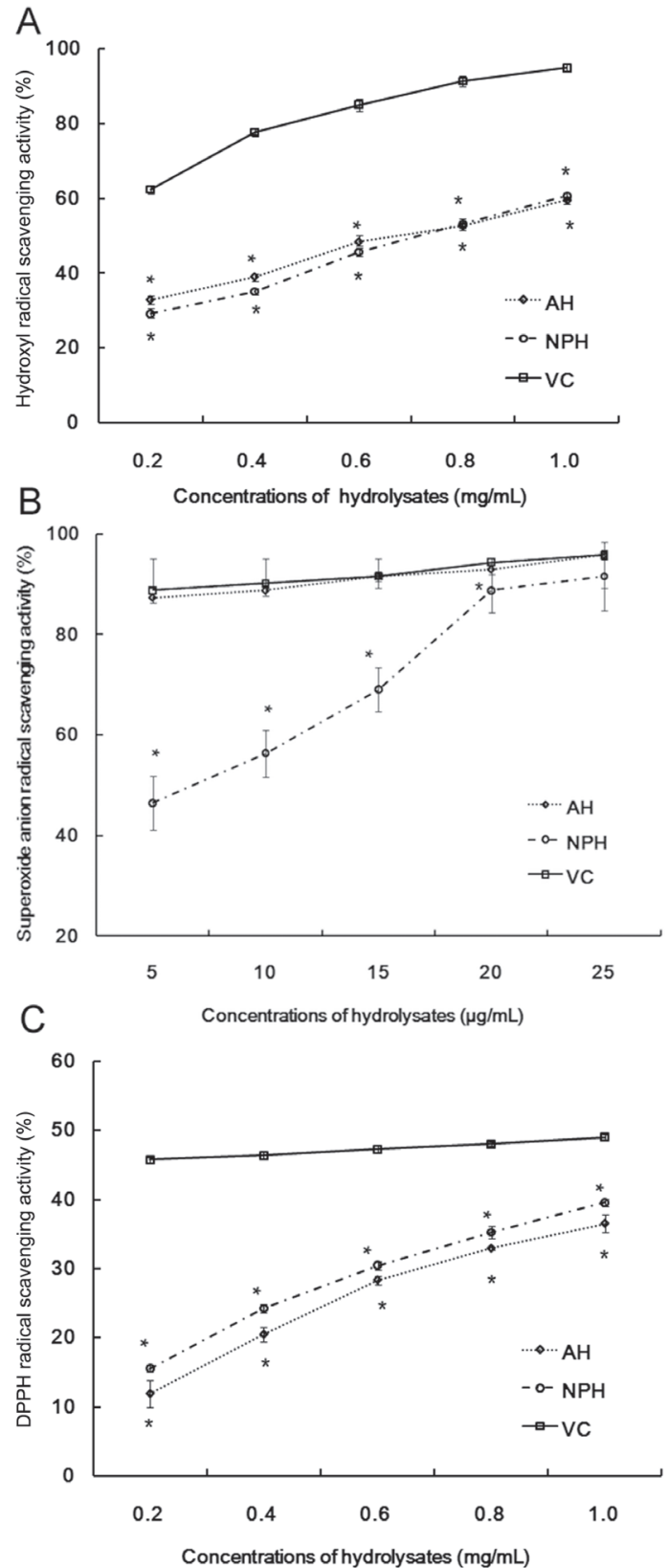

Fig. 2. Hydroxyl radical-scavenging activities (A), superoxide anion radical-scavenging activity (B) and scavenging activity against DPPH free radical (C) of housefly larvae protein hydrolysates alcalase hydrolysate (AH) and neutral proteinase hydrolysate (NPH) at different concentrations. Ascorbic acid (VC) was used as positive control. Values are means $\pm \mathrm{SD}(\mathrm{n}=3)$. Asterisk $\left(^{*}\right)$ indicates significant difference compared with that of VC group $(P<0.05)$ 
The superoxide anion radical-scavenging (SARS) activity of the housefly larvae protein hydrolysates was measured using the phenazine methosulfate (PMS)/NADH system as the superoxide source [27]. NPH showed much lower activity on SARS than $\mathrm{AH}$ at $5-15 \mu \mathrm{g} / \mathrm{mL}(P<0.05)$ (Fig. 2B). For NPH, the increase of SARS activity was rapid at low concentrations and slow at high concentrations. At the concentration of $10 \mu \mathrm{g} / \mathrm{mL}$, both hydrolysates showed more than 50\% SARS activity and exceeded $90 \%$ at the concentration of $25 \mu \mathrm{g} / \mathrm{mL}$. These results indicated that both hydrolysates possessed notable superoxide radicals scavenging activity.

\section{DPPH free radical scavenging activity}

DPPH free radical was widely used to investigate the scavenging activity of some natural compounds and the scavenging activity against DPPH free radical is a quick method to evaluate antioxidant activity [28]. When the DPPH free radical was scavenged by a proton-donating substance, such as an antioxidant, the absorbance at 517 $\mathrm{nm}$ was reduced [29]. Increasing scavenging activities of the DPPH free radical were observed with increased concentrations of the AH and NPH (Fig. 2C). The NPH showed a little higher scavenging activity than $\mathrm{AH}$ at various concentrations $(P<0.05)$. At the concentration of $1.0 \mathrm{mg} / \mathrm{mL}$, the NPH exhibited $39.6 \%$ scavenging activity against DPPH free radical and AH showed $36.5 \%$ scavenging activity. The results revealed that both housefly protein hydrolysates possibly contained certain substances as electron donors which could react with DPPH free radicals.

\section{Reducing power of the hydrolysates}

The reducing power of a given compound can serve as an important indicator of its potential antioxidant activities [30]. The method of Oyaizu [20] was employed to estimate the reducing power of the housefly larvae protein hydrolysates in this study. The reducing power of different hydrolysates was concentration-dependent and the NPH showed higher reducing power than AH $(P<0.05)$ (Fig. 3A). At the concentration of $12 \mathrm{mg} / \mathrm{mL}$, the values were 1.10 and 1.30 for the reducing power of $\mathrm{AH}$ and $\mathrm{NPH}$, respectively. The data indicated that both hydrolysates possessed high reducing power. Both housefly larvae protein hydrolysates can be composed of various unfolded antioxidant peptides, exposed the previous hidden amino acid residues and side chains with antioxidant properties.

\section{Metal-chelating activity}

Transition metal ions, such as ferrous ion, may catalyze the formation of reactive oxygen species that accelerates lipid oxidation. It is desirable to suppress lipid oxidation in foods by chelating the ions and to prevent food from displaying bad off-fla- 
vors, odors, dark colors and producing potentially toxic products [3]. We employed the method based on ferrozine to evaluate the metal-chelating activity of the housefly larvae hydrolysates [21]. The results showed that the metal-chelating ability of both hydrolysates increased dose dependently (Fig. 3B). However, AH displayed much stronger metal-chelating activity than NPH $(P<0.05)$. NPH showed $36.9 \%$ metalchelating activity at the concentration of $25 \mathrm{mg} / \mathrm{mL}$, while $51.6 \% \mathrm{Fe}^{2+}$ ion was chelated by AH, a little lower than $64.6 \%$ of EDTA at the same concentration. The carboxyl and amino groups in the side chains of acidic and basic amino acids of peptides were reported to play important roles in metal ions chelating [31]. The content of acidic and basic amino acids, namely Glu, Asp, Arg and Lys, was notably abundant
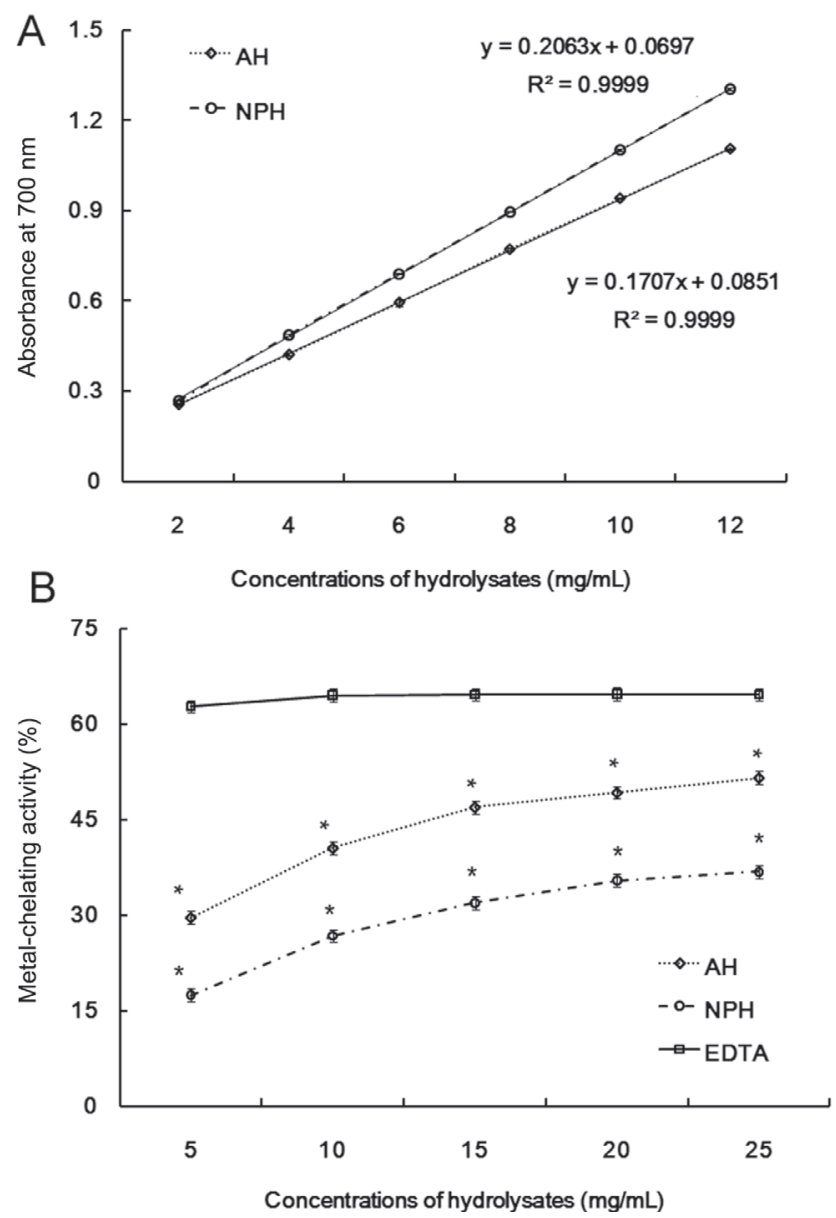

Fig. 3. Reducing power (A) and metal-chelating activity (B) of housefly larvae protein hydrolysates at different concentrations. Abbreviations: $\mathrm{AH}$, alcalase hydrolysate; NPH, neutral proteinase hydrolysate. EDTA was used as positive control for metal chelating activity. Values are means $\pm \mathrm{SD}(\mathrm{n}=3)$. Asterisk

$\left.{ }^{*}\right)$ indicates significant difference compared with that of EDTA group $(P<0.05)$ 
in the housefly larvae protein hydrolysates (Table 1), which probably give rise to metal-chelating activities of the housefly larvae protein hydrolysates.

The antioxidant activities of protein hydrolysates from house larvae were comparable to those of protein hydrolysates obtained from other animal resources $[7,8,11$, 32-34]. The main advantage of using housefly larvae over fishery products lies in the low cost associated with housefly's short life cycle, high fecundity and high activity to convert organic waste into useful materials $[13,14]$.

In summary freeze-dried defatted housefly larvae protein hydrolysates obtained by using alcalase and neutral proteinase showed high antioxidant activities and free radical scavenging activities. The hydrolysates can be used as natural additives with antioxidant properties in feed supplement for animals.

\section{ACKNOWLEDGEMENTS}

This work was supported in part by the grants from the Knowledge Innovation Program of Chinese Academy of Sciences (Grant No. KSCX2-YW-G-040 and KSCX2-YW-N-081), the National Basic Research Program of China (No. 2012CB114100), and the National Natural Science Foundation of China (No. 31272365).

\section{REFERENCES}

1. Beckman, K. B., Ames, B. N. (1998) The free radical theory of aging matures. Physiol. Rev. 78, 547-581.

2. Smith, M. A., Perry, G., Richey, P. L., Sayre, L. M., Anderson, V. E., Beal, M. F., Kowall, N. (1996) Oxidative damage in Alzheimer's. Nature 382, 20-121.

3. Lin, C. C., Liang, J. H. (2002) Effect of antioxidants on the oxidative stability of chicken breast meat in a dispersion system. J. Food Sci. 67, 530-533.

4. Wang, B., Pace, R. D., Dessai, A. P., Bovell-Benjamin, A., Phillips, B. (2002) Modified extraction method for determining 2-thiobarbituric acid values in meat with increased specificity and simplicity. J. Food Sci. 67, 2833-2836.

5. Yu, L., Haley, S., Perret, J., Harris, M., Wilson, J., Qian, M. (2002) Free radical scavenging properties of wheat extracts. J. Agric. Food Chem. 50, 1619-1624.

6. Quian, Z., Jung, W., Kim, S. (2008) Free radical scavenging activity of a novel antioxidative peptide purified from hydrolysate of bullfrog skin, Rana catesbeina Shaw. Bioresour. Technol. 99, 1690-1698.

7. Giménez, B., Alemán, A., Montero, P., Gómez-Guillén, M. C. (2009) Antioxidant and functional properties of gelatin hydrolysates obtained from skin of sole and squid. Food Chem. 114, 976-983.

8. Klompong, V., Benjakul, S., Kantachote, D., Shahidi, F. (2007) Antioxidative activity and functional properties of protein hydrolysate of yellow stripe trevally (Selaroides leptolepis) as influenced by the degree of hydrolysis and enzyme type. Food Chem. 102, 1317-1327.

9. Sakanaka, S., Tachibana, Y., Ishihara, N., Juneja, L. J. (2004) Antioxidant activity of egg-yolk protein hydrolysates in a linoleic acid oxidation system. Food Chem. 86, 99-103.

10. Wang, H., Gao, X. D., Zhou, G. C., Cai, L., Yao, W. B. (2008) In vitro and in vivo antioxidant activity of aqueous extract from Choerospondias axillaris fruit. Food Chem. 106, 888-895.

11. Yu, H. H., Liu, X. G., Xing, R., Liu, S., Guo, Z. Y., Wang, P. B., Li, C. P., Li, P. C. (2006) In vitro determination of antioxidant activity of proteins from jellyfish Rhopilema esculentum. Food Chem. 95, 123-130.

12. Zhu, K. X., Zhou, H. M., Qian, H. F. (2006) Antioxidant and free radical-scavenging activities of wheat germ protein hydrolysates (WGPH) prepared with alcalase. Process. Biochem. 41, 1296-1302. 
13. Hao, Y. J., Jing, Y. J., Qu, H., Li, D. S., Du, R. Q. (2008) Purification and characterization of a thermal stable antimicrobial protein from housefly larvae, Musca domestica, induced by ultrasonic wave. Acta Biol. Hung. 59, 289-304.

14. Jing, Y. J., Hao, Y. J., Qu, H., Shan, Y., Li, D. S., Du, R. Q. (2007) Studies on the antibacterial activities and mechanisms of chitosan obtained from cuticles of housefly larvae. Acta Biol. Hung. 58, $75-86$.

15. Ai, H., Wang, F. R., Yang, Q. S., Zhu, F., Lei, C. L. (2008) Preparation and biological activities of chitosan from the larvae of housefly, Musca domestica. Carbohydr. Polym. 72, 419-423.

16. Hou, L. X., Shi, Y. H., Zhai, P., Le, G. W. (2007) Antibacterial activity and in vitro anti-tumor activity of the extract of the larvae of the housefly (Musca domestica). J. Ethnopharmacol. 111, 227-231.

17. Schägger, H. (2006) Tricine-SDS-PAGE. Nat. Protoc. 1, 16-22.

18. Moore, S. (1963) On the determination of cystine and cysteic acid. J. Biol. Chem. 238, 235-237.

19. Halliwell, B., Gutteridge, J. M. C., Aruoma, O. I. (1987) The deoxyribose method: A simple "testtube" assay for determination of rate constants for reactions of hydroxyl radical. Anal. Biochem. 165, $215-219$.

20. Oyaizu, M. (1986) Studies on products of browning reactions: antioxidative activities of products of browning reaction prepared from glucosamine. Jap. J. Nutr. 44, 307-315.

21. Decker, E. A., Welch, B. (1990) Role of ferritin as a lipid oxidation catalyst in muscle food. J. Agric. Food Chem. 38, 674-677.

22. Chen, H. M., Muramoto, K., Yamauchi, F., Nokihara K. (1996) Antioxidant activity of designed peptides based on the antioxidative peptide isolated from digests of a soybean protein. J. Agric. Food Chem. 44, 2619-2623.

23. Kim, S. K., Kim, Y. T., Byun, H. G., Nam, K. S., Joo, D. S., Shahidi, F. (2001) Isolation and characterization of antioxidative peptides from gelatin hydrolysate of Alaska pollack skin. J. Agric. Food Chem. 49, 1984-1989.

24. Mendis, E., Rajapakse, N., Byun, H. G., Kim, S. K. (2005) Investigation of jumbo squid (Dosidicus gigas) skin gelatin peptides for their in vitro antioxidant effects. Life Sci. 70, 2166-2178.

25. Aruoma, O. I. (1998) Free radicals oxidative stress, and antioxidants in human health and disease. J. Am. Oil Chem. Soc. 75, 199-211.

26. Aurand, L. W., Boonme, N. H., Gidding, G. G. (1977) Superoxide and singlet oxygen in milk lipid peroxidation. J. Dairy Sci. 60, 363-369.

27. Gülçin, İ., Şat, İ. G., Beydemir, Ş., Elmastaş, M., Küfrevioğlu, Ö. İ. (2004) Comparison of antioxidant activity of clove (Eugenia caryophylata Thunb) buds and lavender (Lavandula stoechas L.). Food Chem. 87, 393-400.

28. Mokbel, M. S., Hashinaga, F. (2006) Evaluation of the antioxidant activity of extracts from buntan (Citrus grandis Osbeck) fruit tissues. Food Chem. 94, 529-534.

29. Shimada, K., Fujikawa, K., Yahara, K., Nakamura, T. (1992) Antioxidative properties of xanthan on the antioxidation of soy bean oil in cyclodextrin emulsion. J. Agric. Food Chem. 40, 945-948.

30. Wang, Y. G., Zhu, F. R., Han, F. S., Wang, H. Y. (2008) Purification and characterization of antioxidative peptides from salmon protamine hydrolysate. J. Food Biochem. 32, 654-671.

31. Saiga, A., Tanabe, S., Nishimura, T. (2003) Antioxidant activity of peptides obtained from porcine myofibrillar proteins by protease treatment. J. Agric. Food Chem. 51, 3661-3667.

32. Dong, S., Zeng, M., Wang, D., Liu, Z., Zhao, Y., Yang, H. (2008) Antioxidant and biochemical properties of protein hydrolysates prepared from Silver carp (Hypophthalmichthys molitrix). Food Chem. 107, 1485-1493.

33. Samaranayaka, A. G. P., Li-Chan, E. C. Y. (2008) Autolysis-assisted production of fish protein hydrolysates with antioxidant properties from Pacific hake (Merluccius productus). Food Chem. 107, 768-776.

34. Nalinanon, S., Benjakul, S., Kishimura, H., Shahidi, F. (2011) Functionalities and antioxidant properties of protein hydrolysates from the muscle of ornate threadfin bream treated with pepsin from skipjack tuna. Food Chem. 124, 1354-1362. 